\section{A pandemia e a escrita da História no Tempo Presente}

The pandemic and the writing of the History of Present Time

Michel Silva

\section{RESUMO}

Neste artigo serão discutidos alguns dos aspectos teóricos da prática do historiador do Tempo Presente, problematizando o método, as fontes e a narrativa do cenário de pandemia. No artigo serão utilizados referenciais teóricos que auxiliem na compreensão tanto da escrita da história como da sua prática historiográfica do Tempo Presente, procurando demonstrar a importância e as dificuldades do trabalho do historiador que ademais levar em conta que os fenômenos da aparência são apenas a expressão dessas determinações, manifestas na maior parte dos casos política e culturalmente, e que podem ser investigadas pela História do Tempo Presente.

Palavras-chave: Historiografia; Pandemia; Marxismo.

\section{ABSTRACT}

This article will discuss some of the theoretical aspects of the practice of the historian of the Present Time, problematizing the method, the sources and the narrative of the pandemic scenario. The article will use theoretical references that help in the understanding of both the writing of history and its historiographical practice of the Present Time, seeking to demonstrate the importance and the difficulties of the work of the historian who, in addition to taking into account that the phenomena of appearance are only the expression of these determinations, manifested in most cases politically and culturally, and that can be investigated by the History of the Present Time.

Keywords: Historiography; Pandemic; Marxism

\title{
Resistances
}

INFORMATION

https://doi.org/10.46652/resistances. V2i 4.59

ISSN $2737-6222$ |

Vol. 2 No. 4, 2021, e21059

Quito, Ecuador

Submitted: August 2, 2021 Accepted: October 10, 2021

Published online: October 16, 2021 Continuous publication

General Section | Peer Reviewed

\section{ल)(2)}

open $\mathcal{O}$ access

\section{AUTHOR}

(iD) Michel Silva

Instituto Federal de Educação, Ciência e Tecnologia Catarinense - Brasil michel.silva@ifc.edu.br

Conflict of interest

The author declares that there was no possible conflict of interest. Funding

There was no financial assistance from external parts for this article. Acknowledgments N/A
PUBLISHER

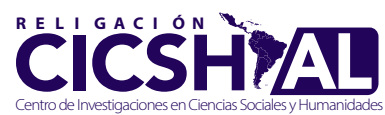




\section{Introdução}

Iniciada em 2020, a pandemia da Covid-19 foi um dos acontecimentos mais traumáticos nos anos recentes em todo o mundo. Mesmo que não seja possível dimensionar o impacto que trará para a humanidade, na medida em interfere no âmbito público e privado da vida de todas as pessoas, deve deixar marcas em toda sociedade, econômica, política e socialmente (Silva, Velho \& Raquel, 2021). Na base disso, está uma crise econômica, cujos elementos principais vinham se mostrando há pelo menos dois anos, e que, contraditoriamente, tanto aumenta a miséria de bilhões de pessoas como aumenta a riqueza dos mais ricos (Silva \& Velho, 2021). Além disso, em relação especificamente à pandemia, se percebe o clima de medo provocado pela proliferação do vírus e o impacto no cotidiano de todos devido à perda de milhões de vidas em todo o mundo.

Para o historiador, esse processo aparece como um desafio dentro do qual precisa encontrar as melhores formas de contribuir, auxiliando na compreensão da realidade ao seu redor. Nesse sentido, nessa área, o campo de pesquisa que talvez possa mais contribuir é a chamada História do Tempo Presente, que nas últimas décadas se consolidou no Brasil. Uma série de publicações disponíveis no Brasil apresentaram discussões acerca da História do Tempo Presente, podendose destacar, entre outras, Chauveau \& Tétart (1999), Delgado \& Ferreira (2014), Dosse (2012), Lohn \& Campos (2017) e Porto Junior (2007).

Esse campo de pesquisa se mostra fundamental neste momento de pandemia, na medida em que se propõe a investigar "um processo em curso, inacabado por definição", lidando com "um ator vivo, acessível e, portanto, sujeito a reações diante das afirmações do historiador" (Rousso, 2016, p. 240). O conceito de "tempo presente" não deve ser considerado "um simples período adicional mais próximo", mas remete-se "em sua acepção extensiva ao que é do passado e nos é ainda contemporâneo, ou ainda, apresenta um sentido para nós do contemporâneo não contemporâneo" (Dosse, 2012, p. 11). Nessa lógica, compreende-se que "a particularidade da história do tempo presente está em que ela se interessa por um presente que é o seu, em um contexto em que o passado não está acabado, nem encerrado" (Rousso, 2016, p. 18).

Essa compreensão implica inclusive num entendimento de História, que, embora não seja exatamente novo, não está presente na compreensão comum das pessoas. Parte-se aqui da compreensão de que "a história não é somente o estudo do passado, ela também pode ser, com um menor recuo e método particulares, o estudo do presente" (Chauveau \& Tétart, 1999, p. 15). Pode-se afirmar que a característica da História do Tempo Presente consiste na "unidade temporal do sujeito e do objeto", na medida em que "o período estudado não está fechado: não há esse elemento de alienação, de alteridade, que é próprio do estudo de períodos mais afastados. Não ocorreu ainda ruptura cronológica entre o tempo dos acontecimentos e o tempo da escritura de sua história" (Lagrou, 2007, p. 36).

Esses elementos permitem ao historiador compreender suas possíveis contribuições no entendimento da dinâmica e dos processos relacionados à pandemia, em uma perspectiva interdisciplinar. Sabe-se que "o historiador pode auxiliar na compreensão de processos econômicos, políticos e sociais, passados ou ainda em andamento, que permitem analisar a realidade contemporânea ou mesmo as ações da sociedade e do Estado no combate à pandemia" (Silva, 2020, p. 2).

Essas contribuições podem abarcar uma diversidade de temas e escopos, auxiliando a sociedade a problematizar e analisar historicamente suas contradições e as necessidades concretas de diferentes classes e categorias. Nesse sentido, 
...pode-se investigar a trajetória de políticas públicas, a situação econômica, as mobilizações de classes ou de outros segmentos sociais, ou seja, diferentes elementos que necessitam de uma compreensão da relação entre passado, presente e futuro. Analisar os impactos e dinâmicas sociais relacionados a outros surtos, epidemias e pandemias ao longo da História pode ajudar a compreender o papel contemporâneo de políticas como a de isolamento, os tratamentos de saúde ou a relação desses fatores com os problemas sociais construídos ao longo de décadas ou mesmo séculos. Permite ainda investigar as ações, em diferentes lugares e contextos históricos, que Estados e governos adotaram não apenas no combate direto contra as doenças, mas também para garantir questões básicas para a manutenção da sociedade, como alimentação, emprego e salário das populações (Silva, 2020, p. 2).

Neste artigo serão discutidos alguns dos aspectos teóricos da prática do historiador no Tempo Presente, problematizando o método, as fontes, o tempo e a narrativa, diante da pandemia e de seu impacto na sociedade, ao mesmo tempo destacando as fundamentais contribuições da dialética marxista. Serão discutidos diferentes elementos da prática do historiador diante dos problemas colocados pelo cenário pandêmico. Neste estudo serão utilizados referenciais teóricos que auxiliem na compreensão tanto da escrita da história como da sua prática historiográfica do Tempo Presente no atual contexto.

\section{Método}

Um processo como a pandemia, que se espalhou pelo mundo e impactou no cotidiano das pessoas, inclusive por meio do adoecimento ou mesmo da morte, afetou a subjetividade de todos, inclusive dos próprios pesquisadores. O cotidiano acaba sendo marcado por um conjunto de informações e, ao estar imerso neles, o historiador corre o risco de perder de vista a complexidade da relação entre passado, presente e futuro. Nesse sentido, um dos primeiros aspectos a se levar em conta passa por analisar criticamente e em sua historicidade os fatos episódios ou conjunturais. Os historiadores do Tempo Presente, diante da escolha de trabalhar questões sensíveis, "tiveram de inventar, senão métodos, pelo menos uma maneira de se colocar na paisagem. Eles tiveram de criar suas hierarquias acerca das testemunhas, tentando dominar seus afetos sem com isso renunciar a suas emoções" (Rousso, 2016, p. 186). Esse historiador se envolve "na marcha do tempo e deve aceitar que seu olhar é apenas parcial, limitado, frágil, bem ao contrário da ilusão científica de dominar o sentido último da história" (Rousso, 2016, p. 187). Portanto, a produção do conhecimento apresenta limites, quando encarada apenas como uma tarefa individual. Sabese que,

...sendo cada objeto do conhecimento infinito em suas características e conexões, não pode ser esgotado em um único ato (finito) do conhecimento. Os homens tentam conhecer o sistema do mundo na sua conexão total, mas jamais poderão cumprir plenamente tal tarefa. Essa é uma contradição que se resolve na evolução infinita e no progresso da humanidade mediante a sucessão - infinita para fins práticos - das gerações humanas: tende-se ao conhecimento absoluto e completo por meio de conhecimentos parciais que, segundo a riqueza da práxis social de cada época, aproxima-se mais ou menos do objeto real (Cardoso, 2012, p. 8).

Essa limitação do olhar faz com que o historiador tenha que analisar o fenômeno para além da sua empiria e de suas experiências subjetivas, por mais que a conjuntura pandêmica o afete em seus sentimentos e em seu cotidiano. Uma compreensão científica da realidade pressupõe a utilização de métodos que permitam analisar as determinações e a totalidade do objeto em estudo. Deve-se, dessa forma, 
... adquirir uma compreensão concreta do objeto como um sistema integral, e não como fragmentos isolados; com todas as interconexões necessárias, e não fora de seu contexto, como uma borboleta cravada no painel de um colecionador; na sua vida e movimento, e não como algo estático e sem vida (Woods \& Grant, 2007, p. 79).

Portanto, uma compreensão dos processos históricos precisa levar em conta as mais variadas dimensões - econômica, política, cultura, entre outras. A pesquisa histórica mostra,

[...] que em cada um dos seus estágios encontra-se um resultado material, uma soma de forças de produção, uma relação historicamente estabelecida com a natureza e que os indivíduos estabelecem uns com os outros; relação que cada geração recebe da geração passada, uma massa de forças produtivas, capitais e circunstâncias que, embora seja, por um lado, modificada pela nova geração, por outro lado prescreve a esta última suas próprias condições de vida e lhe confere um desenvolvimento determinado, um caráter especial - que, portanto, as circunstâncias fazem os homens, assim como os homens fazem as circunstâncias (Marx \& Engels, 2007, p. 43).

Nesse processo, portanto, além de utilizar uma perspectiva objetiva em sua investigação, o historiador parte de uma perspectiva de totalidade, analisando os fenômenos em suas contradições e para além dos elementos perceptíveis apenas pela empiria. Por exemplo, mesmo que discursos políticos ou dados estatísticos possam ser importantes para que o historiador se aproxime do seu objeto, sua investigação não pode se limitar a essas ideias e representações. Esses fenômenos são parte de um todo contraditório e em movimento, cabendo ao historiador buscar se aprofundar nas suas diversas determinações. Com isso, é possível analisar a realidade não apenas pela percepção que as pessoas constroem sobre ela, mas em sua concretude, entendendo que:

[...] não é a consciência que determina a vida, mas a vida que determina a consciência. No primeiro modo de considerar as coisas, parte-se da consciência como do indivíduo vivo; no segundo, que corresponde à vida real, parte-se dos próprios indivíduos reais, vivos, e se considera a consciência apenas como sua consciência (Marx \& Engels, 2007, p. 94).

Certamente que, ao olhar para a realidade em que está inserido, o historiador não poderá se abster de se posicionar e, principalmente, fazer correr pelas linhas de seus textos algum tipo de posicionamento sobre os diversos aspectos dessa conjuntura. Essas percepções contribuem com sua pesquisa, afinal, "antes de ignorar suas próprias inclinações ou sua própria identidade, o historiador deve se servir disso para pôr à sua maneira problemas que não podem ser tratados de modo 'neutro"' (Rousso, 2016, p. 186). Contudo, para que não caia na mera apologia acerca da política imediata ou faça uma propaganda simplória de suas ideias, o uso do método científico pode garantir ao historiador a produção de uma pesquisa que permita compreender as contradições da realidade em análise. Esse método precisa considerar a realidade inserida no processo de produção da vida, sem

[...] se limitar à indagação da autenticidade das fontes e, no máximo, à descoberta da ordem dos eventos que se dão à primeira vista de forma confusa. É preciso que ele também componha sequências de ordens possíveis na realidade, conduza a hipóteses comprováveis e as vá reformulando no decorrer do processo inteiro. Por meio dele, o sujeito organiza ativamente a sua experiência intelectual, em um 
constante intercâmbio entre o momento propriamente empírico e o teorizador (Grespan, 2005, p. 295).

Essa compreensão pode permitir ao historiador escapar de dois riscos principais. Um deles é a centralidade dos acontecimentos, na medida em que, sob o impacto de fatos de caráter conjuntural considerados momentaneamente relevantes, pode-se construir uma narrativa centrada neles, sem mostrar a totalidade dos processos no tempo. O historiador precisa partir da compreensão de que "os eventos não podem ser considerados uma série de aventuras nem inseridos num fio de moral pré-concebida" (Trotsky, 2007, p. 9). Outro risco é o personalismo, ou seja, construir uma história centrada em certas figuras de destaque momentâneo, especialmente políticas, na medida em que suas ações se destacam na conjuntura, embora suas ações sejam a expressão individual de ações coletivas de partidos, associações e grupos econômicos. Nesse tema, cabe lembrar que "os homens fazem a sua própria história; contudo, não o fazem de livre e espontânea vontade, pois não são eles quem escolhem as circunstâncias sob as quais ela é feita, mas estas Ihes foram transmitidas assim como se encontram" (Marx, 2011, p. 25).

Concebe-se, portanto, a história como movimento contraditório, com raízes na realidade concreta e na totalidade, cabendo ao historiador identificar e problematizar suas várias determinações. Na pandemia, em que as sensibilidades estão aguçadas pela tragédia que percorre as ruas em todo mundo, onde o luto é uma presença permanente, é importante que o historiador não esconda suas percepções mais subjetivas, mas, a partir dessas experiências e principalmente munido do método científico, desnude os processos que marcam implícita e explicitamente a sociedade.

\section{O problema das fontes}

Outro desafio enfrentado pelo historiador do Tempo Presente diante não apenas da pandemia, mas também da ampliação da informatização da sociedade contemporânea, passa pela abundância de fontes e pela grande diversidade no que se refere às suas características. Podese constatar que o problema para o historiador "em nosso tempo infinitamente burocratizado, documentado e inquiridor" está no "excesso incontrolável de fontes" e não na "escassez das mesmas" (Hobsbawm, 2011, p. 254). Na pandemia, em um primeiro momento, o historiador se viu diante de pelo menos dois problemas:

Por um lado, a impossibilidade de acesso às fontes, na medida em que os principais acervos - bibliotecas, museus, arquivos, entre outros - encontram-se fechados ou com acesso limitado. Por outro lado, o uso de fontes orais é limitado pela necessidade de quarentena em vigor, com suas diferentes fases de fechamento e flexibilização, desde o mês de março, dificultando o contato próximo entre as pessoas e, consequentemente, a realização de entrevistas (Silva, 2020, p. 1).

O desenvolvimento tecnológico auxiliou na superação dessas dificuldades, permitindo um acesso maior a documentos e outras fontes. Para superar ambas as dificuldades, muitos acervos

[...] têm fontes organizadas, digitalizadas e disponibilizadas em espaços virtuais. Quanto às entrevistas, podem ser realizadas por meio de aplicativos de conversa e de videoconferência. Contudo, ainda que seja possível essas formas alternativas, elas esbarram, por um lado, no fato de somente parte dos acervos ser digitalizado ou nas dificuldades técnicas ou mesmo a frieza do mecanismo virtual no estabelecimento das conversas (Silva, 2020, p. 2). 
Esses elementos se complexificam se forem considerados outros aspectos referentes às fontes. Por meio da internet pode-se encontrar os mais variados tipos de textos, sons e vídeos, que passam desde por programas com fins educativos e vão até pequenas postagens sobre o cotidiano das pessoas. Constata-se que "o crescimento das fontes digitais da segunda metade do século XX aos nossos dias foi tão grande que tem afetado as formas de se relacionar com o texto impresso, processo que tem afetado também o campo historiográfico" (Rodrigues, 2014, p. 136). Essa variedade de materiais, à qual se pode acrescentar a digitalização de uma variedade de documentos ou mesmo o material preparado para publicação no espaço virtual, também pode servir como fontes para a História do Tempo Presente.

O historiador se encontra em um cenário contraditoriamente marcado por restrições (de acesso a acervos) e abundâncias (no que se refere às formas de produção), sendo preciso levar em conta dois cuidados principais. Por um lado, diante da abundância de fontes, cabe ao historiador identificar o que de fato pode contribuir com a sua pesquisa e escrita, procurando adaptar as técnicas comuns a outros tipos de fontes. Não significa minimizar ou desqualificar algumas das fontes disponíveis, que podem ser pertinentes para outras pesquisas, mas saber considerar aquelas que de fato podem auxiliar em seu trabalho, sem que perca a noção da totalidade. Essas escolhas devem ajudar o historiador a se aproximar do objeto e, ao mesmo tempo, identificar como ele se insere no movimento contraditório da realidade.

Outro problema passa pela preservação e guarda dessa abundante, variada e fragmentada quantidade de fontes. Os métodos consolidados de organização de acervos não estão devidamente preparados para, por exemplo, fontes oriundas das redes sociais ou para arquivamento de documentos de texto digitais. Nessa situação, deve-se levar em conta que "não se pode simplesmente transpor metodologias", afinal "tais documentos trazem à cena uma infinidade de abordagens possíveis” (Rodrigues, 2014, p. 143). Esse é um caminho ainda a ser percorrido, cujas inciativas ainda não se encontram consolidadas.

No ambiente virtual, muitas das fontes se caracterizam pelo efêmero, devido ao fluxo constante das redes sociais e a questões técnicas relacionadas ao ambiente virtual. Essas dificuldades colocam como problema, entre outros, a facilidade de acesso por parte do conjunto das pessoas. Hoje circulam um amplo conjunto de informações pelas redes sociais, sites, blogs e todo o tipo de plataforma acessível pela internet. Isso torna muito mais fácil a circulação de informações parciais ou mesmo falsas. Esse problema afeta até mesmo o jornalismo, no qual a desinformação “tornou-se um fenômeno comum em nossa época. O ambiente digital reforçou no senso comum o descompromisso com a informação jornalística capaz de se apresentar como conhecimento dos aspectos singulares da realidade" (de Souza, 2019, p. 4).

Nos últimos anos, antes mesmo da pandemia, a difusão de informações falsas se tornou um problema em todo o mundo, inclusive com impactos políticos, afetando, por exemplo, eleições em diferentes países, como Brasil, Estados Unidos e Grã-Bretanha. Essas chamadas fakes news podem ser definidas como informações que, mesmo sem qualquer comprovação de veracidade, são utilizadas no debate público e inclusive científico, afetando a opinião pública, impactando na percepção que a sociedade tem dos fatos e confundindo suas escolhas. Mas elas também podem significar a manipulação de informações verídicas: “Mais do que o simples falseamento de acontecimentos e informações, nos deparamos com um fenômeno que também consegue articular dados corretos, acontecimentos às intepretações subjetivas e manipulações malintencionadas sobre conteúdos e informações" (Meneses, 2020, p. 46). 
Sua influência é relativa, podendo ser enfraquecida com o debate público e a difusão de fatos com base consistentes e feito de forma coerente, mas exigindo uma atenção que não seria necessária se houvesse o cuidado e a intenção de não divulgar mentiras. Na sociedade dividida em classes antagônicas esse fenômeno não é exatamente uma novidade, considerando que:

[...] a produção de ideias, de representações, da consciência, está, em princípio,
imediatamente entrelaçada com a atividade material e com o intercâmbio material
dos homens, com a linguagem da vida real. O representar, o pensar, o intercâmbio
espiritual dos homens ainda aparecem, aqui, como emanação direta de seu
comportamento material (Marx \& Engels, 2007, p. 93).

O novo nas fake news está principalmente na facilidade com que se proliferam, servindo-se da tecnologia não para facilitar a comunicação e a difusão de informações para o maior número possível de pessoas, mas para divulgar mentiras com fins explicitamente nocivos e até mesmo criminosos. O historiador pode se defrontar com esses problemas em sua escrita, na medida em que precisa avaliar um conjunto de fontes, cujo acesso em muitos casos pode ser parcial e impreciso e seu conhecimento insuficiente. Por isso, ainda que a fonte seja central na escrita da história, é fundamental não a ter como uma tábua de salvação que vai resolver todos os problemas da escrita. Sabe-se que a fonte:

[...] apenas esclarece certas áreas daquilo que as pessoas fizeram, sentiram e
pensaram. O que normalmente devemos fazer é reunir uma ampla variedade de
informações em geral fragmentárias: e para fazer isso precisamos, se me perdoam
a expressão, construir nós mesmos o quebra-cabeça, ou seja, formular como tais
informações deveriam se encaixar (Hobsbawm, 2011, p. 224-5).

No uso das fontes, na busca por encaixar as peças do emaranhado de elementos que compõe sociedade e identificar suas contradições em movimento, o historiador precisa levar em conta a compreensão que embasa a análise do concreto. Essa análise, ainda que parta dos fenômenos aparentes, precisa da abstração para identificar suas variadas determinações. Portanto,

quando contemplamos pela primeira vez o mundo que nos rodeia, vemos uma
imensa e surpreendente série de fenômenos complexos; uma rede intrincada de
mudanças aparentemente sem final, causa e efeito, ação e reação. A força motriz da
investigação científica é o desejo de obter uma visão racional deste confuso labirinto,
o desejo de entendê-lo para poder conquistá-lo. Buscamos leis que possam separar
o geral do particular, o acidental do necessário, e que nos permitam compreender as
forças que promovem os fenômenos que enfrentamos (Woods \& Grant, 2007, p. 33).

O historiador, ao se defrontar com a realidade, se vê diante de um conjunto de fragmentos que precisa organizar, selecionar e interpretar, verificando suas possíveis conexões. Em tempo pandêmicos, em que uma parcela da população passou a maior parte do tempo em ambientes virtuais, sendo bombardeado por informações das mais variadas, fossem falsas ou verdadeiras, o historiador se defronta com desafios ainda maiores. Nesse cenário, a despeito das dificuldades iniciais, precisou encontrar formas que permitam realizar o seu trabalho, mesmo diante dos percalços que lhe dificultam a caminhada.

\section{O tempo e a narrativa}

Essa compreensão permite escrever uma história do Tempo Presente que, ao mesmo tempo, investiga os processos em aberto e os relaciona ao passado. Essa escrita não pode se limitar a uma 
descrição da crise contemporânea ou à narração de fatos episódicos recentes, o que limitaria sua escrita a uma crônica de acontecimentos imediatos. Como se afirmou acima, o historiador precisa buscar compreender o movimento contraditório da realidade e dos processos que determinam a situação contemporânea. O pesquisador deve ter em mente que "fazer história é precisamente criar uma mediação, estabelecer uma ponte entre um passado frequentemente ininteligível para as gerações posteriores e um presente que precisa de um enraizamento temporal, de uma profundidade de campo, qualquer que seja sua duração" (Rousso, 2016, p. 235).

O tempo, neste caso, não pode ser visto como uma mera representação que varia a partir das percepções pessoais, mas em seus elementos objetivos, ainda que, como qualquer pessoa, o historiador participe "das concepções culturais sobre a temporalidade vigente em sua própria sociedade" (Cardoso, 1988, p. 31). O tempo deve ser entendido como "a expressão do fato de que a matéria existe em um estado de mudança constante. O destino e a necessidade de todas as coisas materiais é mudar para se converter em algo diferente do que eram" (Woods \& Grant, 2007, p. 146). Essa concepção acerca do tempo impacta na compreensão de história, entendida como:

[...] o suceder-se de gerações distintas, em que cada uma delas explora os materiais, os capitais e as forças de produção a ela transmitidas pelas gerações anteriores; portanto, por um lado ela continua a atividade anterior sob condições totalmente alteradas e, por outro, modifica com uma atividade completamente diferente as antigas condições (Marx \& Engels, 2007, p. 40).

O presente está impregnado de elementos do passado, na medida em que os processos atuais, em maior ou em menor grau, têm relação com o passado. Por isso, a história deve:

[...] ser sempre escrita segundo um padrão situado fora dela; a produção real da vida aparece como algo pré-histórico, enquanto o elemento histórico aparece como algo separado da vida comum, como algo extra e supraterreno. Com isso, a relação dos homens com a natureza é excluída da história, o que engendra a oposição entre natureza e história. Daí que tal concepção veja na história apenas ações políticas dos príncipes e dos Estados, lutas religiosas e simplesmente teoréticas e, especialmente, que ela tenha de compartilhar, em cada época histórica, da ilusão dessa época (Marx \& Engels, 2007, p. 43-4).

Essa compreensão da escrita, desenvolvida no século XIX, se mostra pioneira diante de uma historiografia que predominou ainda em grande parte do século XX. Sabe-se que "a maior parte da história no passado era escrita para a glorificação e talvez para o uso prático dos governos" (Hobsbawm, 2011, p. 216). Essa história expressava as ideias das classes dominantes, de cuja influência, contemporaneamente, o historiador não está livre. Para um entendimento correto da questão, é preciso considerar que:

[...] as ideias da classe dominante são, em cada época, as ideias dominantes, isto é, a classe que é a força material dominante da sociedade é, ao mesmo tempo, sua força espiritual dominante. A classe que tem à sua disposição os meios da produção material dispõe também dos meios da produção espiritual, de modo que a ela estão submetidos aproximadamente ao mesmo tempo os pensamentos daqueles aos quais faltam os meios da produção espiritual (Marx \& Engels, 2007, p. 47). 
Esse entendimento é fundamental para que o historiador possa destacar em sua produção as contradições em movimento. O historiador do tempo presente, ao fazer parte da realidade que está investigando, não tem como se colocar como alguém neutro, sendo um observador e um participante dos processos, portanto, uma testemunha. Deve-se considerar que "a testemunha que vê, a testemunha que fala, a testemunha que escreve, seja o próprio historiador, desempenha claramente um papel essencial, uma vez que é um mediador primário, para não dizer único" (Rousso, 2016, p. 282). Para não fazer da história do Tempo Presente uma mera descrição de fatos e fenômenos aparentes, o pesquisador deve ter clareza de seu método e de sua compreensão da realidade, sob risco de, na conjuntura pandêmica, diante da abundância de informações difundidas no cotidiano, se limitar a repassar informações de utilidade prática e imediata, e não realizar uma compreensão da sociedade em sua totalidade e variadas determinações.

\section{Considerações finais}

O historiador, assim como outros cientistas sociais, é de fundamental importância no contexto de pandemia, ainda que suas pesquisas, em sua maioria, não apresentem resultados palpáveis e imediatos. Na recente conjuntura marcada pela Covid-19, sabe-se que "os historiadores podem contribuir no combate à pandemia, auxiliando a sociedade a entender os acontecimentos do presente em sua historicidade", elucidando "processos, ações e contradições” (Silva, 2020, p. 3).

O historiador, ao analisar a sociedade, deve identificar as determinações e os movimentos contraditórios que marcam a dinâmica da sociedade. Deve, ademais, levar em conta que os fenômenos da aparência são apenas a expressão dessas determinações, manifestas na maior parte dos casos política e culturalmente, e que podem ser investigadas pela História do Tempo Presente. O processo de abstração, desenvolvido pelo materialismo dialético, enquanto expressão do desenvolvimento científico dos últimos séculos, mostra-se uma de suas principais ferramentas.

Os historiadores podem analisar as contradições não apenas de um passado distante, mas igualmente do tempo em que está inserido. Pode, ademais, mostrar os processos em abertos e apontar para caminhos possíveis a serem trilhados, de tal forma a garantir a superação da crise econômica, sanitária e política que vem marcando o mundo nos últimos dois anos em meio à pandemia da Covid-19. Pode, enfim, mostrar as rachaduras que marcam a sociedade e apontar para a possibilidade de sua superação por meio de uma nova sociedade.

\section{REFERÊNCIAS}

Cardoso, C. (1988). Ensaios racionalistas. Campus.

Cardoso, C. (2012). História e conhecimento: uma abordagem epistemológica. In C. Cardoso \& R. Vainfas (Org.). Novos Domínios da História. Elsevier.

Chauveau, A., \& Tétart, P. (1999). Questões para a História do Presente. In: A. Chauveau, \& P. Tétart. (org.). Questões para a história do presente. EDUSC.

Delgado, L., \& Ferreira, M. (2014). História do Tempo Presente. FGV.

de Souza, R. B. R. (2019). “Fake news”, pós-verdade e sociedade do capital: o irracionalismo como motor da desinformação jornalística. Revista FAMECOS, 26(3), e33105. https://doi.org/10.15448/19803729.2019.3.33105

Dosse, F. (2012). História do tempo presente e historiografia. Revista Tempo e Argumento 4(1), 05-22. http:// dx.doi.org/10.5965/2175180304012012005

Grespan, J. (2005). Considerações sobre o método. In C. Bassanezi Pinsky. (Org.). Fontes Históricas. Contexto. 
Hobsbawm, E. (2011). Sobre História. $2^{\mathrm{a}}$ ed. Companhia das Letras.

Lagrou, P. (2007). Sobre a atualidade da história do tempo presente. In G. Porto Júnior (Org.). História do tempo presente. EDUSC.

Lohn, R. L., \& Campos, E. C. de. (2017). Tempo Presente: entre operações e tramas. História Da Historiografia, 10(24), 97-103. https://doi.org/10.15848/hh.voi24.1176

Marx, K. (2011). O 18 brumário de Luís Bonaparte. Boitempo.

Marx, K., \& Engels, F. (2007). A ideologia alemã. Boitempo.

Meneses, S. (2020). Bolsonarismo: um problema "de verdade" para a história. In B, Klem, M. Pereira \& V. Araujo (Org.). Do Fake ao Fato: des(atualizando) Bolsonaro. Milfontes.

Rodrigues, P. E. (2014). A teia, a tela e o tempo: internet e história do tempo presente. Revista Tempo E Argumento, 6(12), 131-150. https://doi.org/10.5965/2175180306122014131

Rousso, H. (2016). A última catástrofe: a História, o presente, o contemporâneo. FGV.

Silva, M. (2020). O papel do historiador diante da pandemia. Boletim de Conjuntura, 3(7), 1-3. http://dx.doi. org/10.5281/zenodo.3885459

Silva, M. G. da, \& Velho, R. S. (2021). Capitalismo, crise e educação. Revista Labor, 1(25), 143-156. https://doi. org/10.29148/labor.vii25.62704

Silva, M. G. da, Scopel Velho, R., \& Raquel, R. (2021). Trabalho e educação em tempos de pandemia: relato de experiência. Extensão Tecnológica: Revista De Extensão Do Instituto Federal Catarinense, 8(15), 304310. https://doi.org/10.21166/rext.v8i15.1796

Trotsky, L. (2007). História da revolução russa. Sundermann.

Woods, A. \& Grant, T. (2007). Razão e revolução: filosofia marxista e ciência moderna. Luta de Classes.

\section{AUTHOR}

Michel Goulart da Silva. PhD in History from the Federal University of Santa Catarina (UFSC). $\mathrm{He}$ is doing post-doctoral training in the Graduate Program in Education at the State University of Santa Catarina (UDESC). 